\title{
A SUSTENTABILIDADE NOS TERRITÓRIOS DO MILHO CRIOULO: OLHARES PARA ANCHIETA/SC E IBARAMA/RS
}

\author{
Antônio Valmor de Campos* \\ Kelly Perlin Cassol** \\ Carmen Rejane Flores Wizniewsky***
}

\begin{abstract}
Resumo
O desenvolvimento sustentável representa a expectativa de melhores condições de vida para toda a população. Esperase verificar se nos territórios do milho crioulo de Ibarama e Anchieta é possível identificar aspectos que contemplam essa concepção. Também se pretende averiguar se os agricultores que cultivam milho crioulo optam por um modelo de desenvolvimento, que tenha preocupações efetivas com o equilíbrio social e ambiental. Os resultados da pesquisa empírica foram analisados sob a ótica da sustentabilidade que concilie o de crescimento econômico com as organizações culturais, associativas que priorizam o modelo agrícola do policultivo, da agroecologia e da autonomia, utilizando as sementes crioulas, principalmente a de milho. Isso é visível nos "territórios do milho crioulo", como em Ibarama/ RS e Anchieta/SC. Nesses locais, um grupo de agricultores se organiza para praticar e defender o desenvolvimento sustentável, que se concretiza pela utilização das sementes crioulas, especialmente do milho. Os pesquisadores/autores realizaram pesquisas nesses territórios para a elaboração das suas dissertações de mestrado. Em Anchieta a pesquisa realizada pelo autor 1 , ocorreu no ano de 2004. Porém, isso o aproximou desse território, mantendo as visitas in loco, até a realização de doutorado no mesmo território, concluído no corrente ano. A segunda autora, concluiu seu mestrado no território de Ibarama, no ano de 2013. Isso permitiu conhecer e analisar as atividades desenvolvidas por esses agricultores. Os dados foram obtidos por meio de entrevistas semiestruturadas e a partir de informações colhidas em reuniões, encontros, visitas e feiras sobre o milho crioulo. O presente artigo apresenta, além da descrição dessas experiências, mediante noções teóricas sobre a sustentabilidade e as interfaces com o milho crioulo. Demonstra-se, ainda, a possibilidade de o cultivo do milho crioulo ser catalisador de práticas agrícolas votadas para o desenvolvimento sustentável, com menor impacto ambiental e melhor justiça social.
\end{abstract}

Palavras-chave: Sustentabilidade. Milho crioulo. Território do milho crioulo. Agricultores camponeses.

\footnotetext{
* Doutor em Geografia pela Universidade Federal de Santa Maria (UFSM). Mestre em Educação pela Universidade do Vale do Rio dos Sinos (Unisinos). Graduado em Ciências e Matemática e Licenciatura Plena em Ciências Biológicas pela Fundação Educacional do Alto Uruguai Catarinense. Graduado em Direito pela Universidade Regional Integrada/Campus Frederico Westphalen. Professor do Magistério Superior da Universidade Federal da Fronteira Sul (UFFS), Campus Chapecó/SC. E-mail: prof.antoniocampos@gmail.com

** Doutoranda pela Universidade Federal de Santa Maria (UFSM), no Programa de Pós-Graduação em Geografia (PPGEO). E-mail: perlinkelly@gmail.com

*** Doutora em Geografia, Revalidação de Título no Exterior pela Universidade Federal de Santa Catarina e Doutorado em Geografia e Ciências do Território da Universidad de Córdoba - Espanha. Docente junto ao Programa de Pós-Graduação em Geografia (PPGEO) na Universidade Federal de Santa Maria (UFSM). E-mail: carmenrejanefw@gmail.com
} 


\section{Introdução}

A sustentabilidade é um tema presente em diversos debates; no entanto, ainda há diferenças de compreensão do seu significado. Essas divergências, geralmente, não são decorrentes do desconhecimento sobre o tema, mas da posição que cada grupo social assume sobre o modelo de desenvolvimento. Este artigo trata das concepções dos tipos de desenvolvimento, que são aplicados e praticados no atual modelo de produção. Isso impacta diretamente na tomada de posição por atitudes sustentáveis, como é possível considerar na visão dos agricultores camponeses, que cultivam milho crioulo.

Este texto sintetiza informações armazenadas a partir de pesquisas, realizadas inicialmente para a elaboração da Dissertação de Mestrado dos pesquisadores, no ano de 2004, no Município de Anchieta e no ano de 2012, no Município de Ibarama, junto aos agricultores dos territórios do milho crioulo desses locais. Posteriormente, as pesquisas tiveram continuidade, com a participação dos pesquisadores em atividades de formação, de discussão e de socialização de saberes desses agricultores, sobre as sementes crioulas, especialmente do milho.

Também constam neste artigo diversas contribuições dos levantamentos empíricos realizados por pesquisadores e acadêmicos da Universidade Federal de Santa Catarina (UFSC), através do Centro de Ciência Agrárias/Departamento de Fitotecnia/Núcleo de Estudos em Agrobiodiversidade (NEABio) e da Universidade Federal de Santa Maria (UFSM), realizados pelo Grupo de Pesquisa Agroecologia, Agrobiodiversidade e Sustentabilidade Professor José Antônio Costabeber.

As fontes utilizadas na pesquisa teórica são livros e documentos resultantes de catalogação, de dissertações, de teses e de publicações de artigos científicos, acerca da experiência da experiência de sustentabilidade que tem na sua base estrutural o milho crioulo.

A intenção é tratar a sustentabilidade em seu amplo espectro, demonstrando o seu comprometimento com equilíbrio ambiental, social e econômico. A discussão está pautada a partir de duas experiências de cultivo do milho crioulo. Uma delas, no Município de Ibarama, na Região Centro Sul riograndense. A outra no Município de Anchieta/SC, localizado no Extremo Oeste de Santa Catarina. Os locais foram escolhidos por representarem as experiências referenciais no cultivo e melhoramento de sementes milho crioulo no Brasil.

Nesses dois municípios há um grupo de agricultores que cultiva em suas propriedades as sementes crioulas, principalmente o milho. Além do diferencial no plantio de sementes crioulas, eles desenvolvem suas atividades, tendo como base a prática da agricultura tradicional, normalmente agroecológica ou com uso reduzido de agroquímicos. 
O texto está dividido em três blocos, a fim de facilitar a compreensão da discussão proposta. A primeira parte trata das questões relacionadas com a produção do milho crioulo e os instrumentos - técnicas, práticas e saberes tradicionais - utilizados pelos agricultores no cultivo do milho crioulo, demonstrando as contribuições do mesmo com o desenvolvimento local e regional, com a presença de fortes traços de sustentabilidade.

$\mathrm{Na}$ segunda parte aborda-se a sustentabilidade com a intenção de discutir as diferentes visões inerentes ao tema, bem como analisar os elementos ambientais e sociais envolvidos. Trata-se de uma reflexão teórica, com base em diversos autores.

O terceiro momento contempla as práticas desenvolvidas pelos agricultores que cultivam o milho crioulo, na tentativa de contribuir na compreensão de como a produção do milho crioulo - ao territorializar práticas e saberes - pode contribuir com sustentabilidade nos Municípios onde estão localizados os territórios do milho crioulo.

Portanto, a expectativa é que o presente estudo seja capaz de proporcionar uma reflexão acerca da sustentabilidade, suas diferentes concepções e como ela depende de apropriações e posicionamentos culturais, que resultam opções de produção e modos de vida, com destaque para a interação com os agricultores que cultivam milho crioulo em Ibarama e Anchieta, demonstrando como esse cultivar pode contribuir com a sustentabilidade ambiental e social nos contextos investigados.

\section{Procedimentos metodológicos}

O presente artigo é escrito a partir de detalhado levantamento bibliográfico e documental sobre os temas abordados, tendo-se o cuidado para a busca de referências que ofereceram consistência e seriedade para a compreensão da problemática em discussão. Foi realizada a pesquisa de campo, a qual aconteceu por ocasião das pesquisas de mestrado dos autores e, também, de dados obtidos a partir de eventos relacionados com o milho crioulo, como feiras, formação sobre a utilização de sementes e outros. Os dados foram analisados utilizando o método dialético, buscando-se comparativos com produções teóricas relacionadas.

Além das pesquisas de mestrado, os autores realizaram visitas in loco, entre os anos de 2011 a 2017, objetivando observar as atividades desenvolvidas nas pequenas propriedades dos agricultores que cultivam milho crioulo no Município de Ibarama/RS. No Município de Anchieta/ $\mathrm{SC}$, as visitas in loco, aconteceram do ano de 2005 a 2017. O mapa a seguir, apresenta a localização geográfica dos municípios, de Ibarama, no Estado do Rio Grande do Sul e de Anchieta, no Estado de Santa Catarina onde a pesquisa foi realizada. 


\section{Mapa dos municípios de Anchieta/SC e Ibarama/RS}

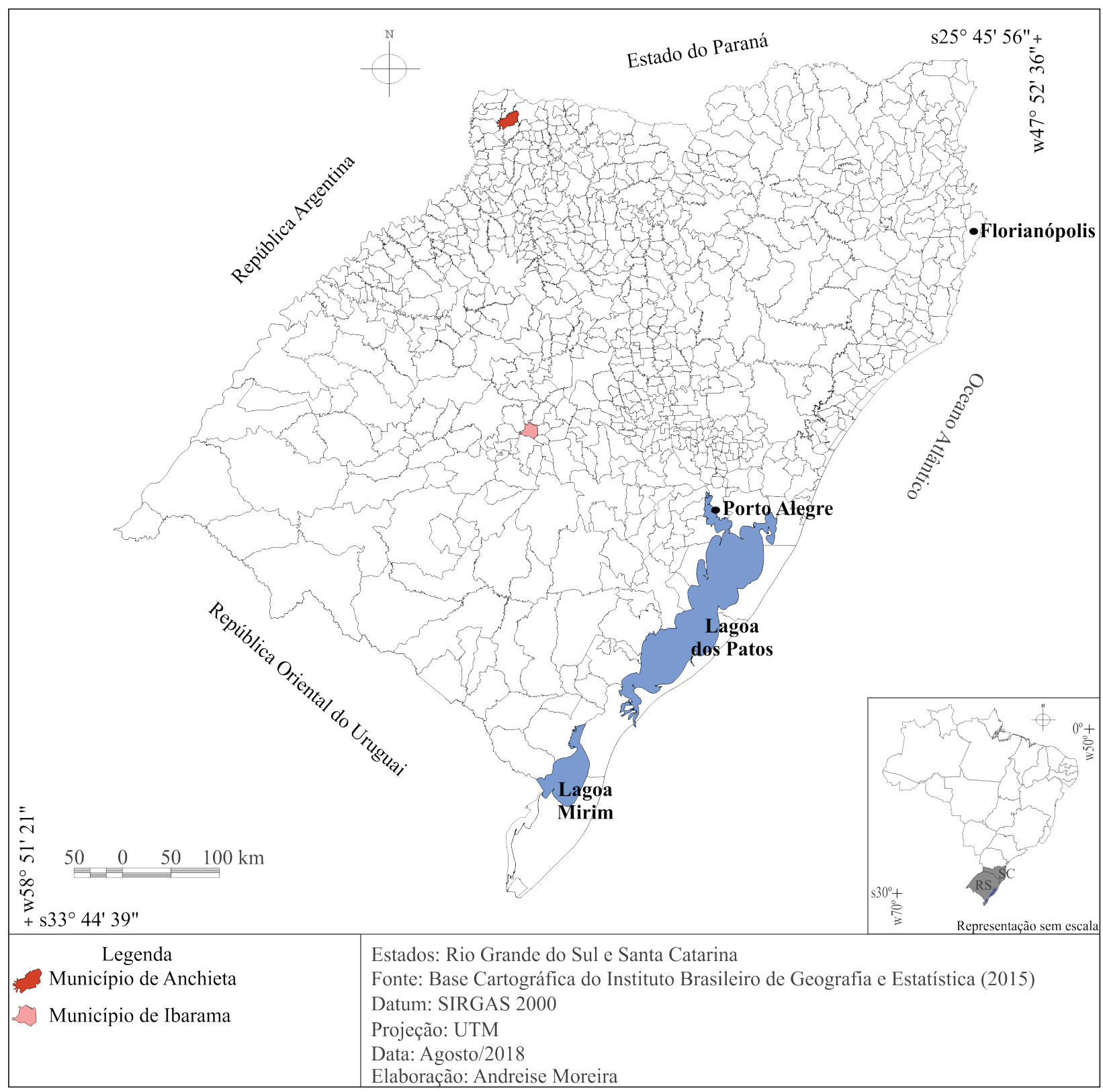

No período de acompanhamento foram realizadas atividades de interação com os agricultores, participando de discussões, reuniões, eventos, além das visitas nas residências, sendo possível assimilar as intenções ao assumirem o compromisso com um desenvolvimento, que resiste às influências dos pacotes tecnológicos para a agricultura.

Foi observado o nível de comprometimento dos agricultores camponeses, com uma proposta de agricultura que valoriza a terra e respeita a natureza, na intenção de analisar as suas convicções sobre as práticas utilizadas na agricultura e se estas estão voltadas para a 
sustentabilidade, analisando-se como o milho crioulo se torna um dos instrumentos utilizado pelos agricultores para garantir que suas atividades estejam em consonância com o equilíbrio ambiental e social.

Portanto, as informações apresentadas estão comprometidas com a representação das experiências observadas na produção do milho crioulo e sua relação com a sustentabilidade, em seus aspectos ambientais, sociais e econômicos. As discussões nesse ensaio representam a realidade observada, com coerência, postura ética e preocupação científica. As fontes utilizadas são documentos que se encontram disponíveis em diversos espaços de acesso público, permitindo o aprofundamento de estudos sobre a situação.

Após as observações, leituras e buscas sobre o tema, foi realizada análise dos dados disponíveis levando em consideração a complexidade do tema, inclusive por divergências na comunidade científica sobre a questão das sementes crioulas e também da compreensão de sustentabilidade. Portanto, o tema é propício ao amplo debate, carecendo de um olhar interdisciplinar e uma compreensão holística sobre a sustentabilidade, permitindo que os seus diversos componentes que lhes dão sustentação sejam avaliados.

Em decorrência da complexidade do tema e das diferentes visões que pairam sobre o ele, utilizou-se como suporte o Método Dialético, permitindo uma reflexão mais crítica dos conflitos presentes no território do milho crioulo e sua relação estabelecida com a sustentabilidade. O Método Dialético permitiu que as reflexões fossem realizadas considerando a realidade das experiências observadas e as condições sociais nas quais estão envolvidos os agricultores. Por exemplo, avaliando a relação da agricultura camponesa com o capital, da produtividade do milho crioulo em comparativo com as demais sementes - híbridas e transgênicas -, além dos aspectos relacionados com as preocupações desses agricultores com as questões socioambientais.

\section{Considerações sobre o milho crioulo}

A base alimentar no mundo é considerada estreita, inclusive dita perigosa, para alguns, pois são apenas "meia dúzia" de espécies vegetais que são utilizadas na produção de alimentos. Também, no caso de animais, são poucas as espécies utilizadas para a produção de carnes e derivados. Acerca da produção de cereais, destacam-se a soja, o milho, o trigo e o feijão. Porém, o milho é o que apresenta uma maior abrangência de utilização, indo da produção de combustível ao consumo in natura por humanos. Na intenção de facilitar a compreensão, é importante considerar que:

O milho, uma gramínea altamente prolífera, que se mistura com a alma de muitos povos, um dos cereais mais importantes do mundo 
com grãos de diversas formas e cores, produz espigas com menos de cinco centímetros e outras com até 60 centímetros, com grãos muito pequenos como o milho pipoca, tendo por largura do grão de 2 a 20 milímetros. (CANCI, 2002, p. 9).

A discussão nesse ensaio é direcionada ao milho crioulo, o qual guarda características específicas. A respeito dessa condição, explica Gabriel Moreno Bernardo Gonçalves (2016, p. 27): "As variedades crioulas são popularmente conhecidas por serem conservadas, selecionadas, multiplicadas e cultivadas por agricultores ao longo de gerações de cultivo ou que não tenham passado por melhoramento formal".

Como a intenção é demonstrar a propensão de o milho crioulo ser mais adequado ao projeto de desenvolvimento sustentável, é necessário refletir sobre os argumentos dos defensores da utilização do milho crioulo para essa finalidade: "Os milhos crioulos são originários das raças e variedades dos índios das três Américas" (CANCI, 2002, p. 9). Portanto, estariam mais adaptados para o equilíbrio ambiental. Também para os defensores dos crioulos é explícito o comprometimento de quem o cultiva com a sustentabilidade ambiental e social.

Normalmente, o agricultor que cultiva milho crioulo não utiliza agroquímicos - quando o faz é em pequena quantidade facilitando a manutenção do equilíbrio: "[...] De um modo geral, um padrão de sustentabilidade ecológica seria dado pelas condições das águas, dos solos, das plantações e pela preservação da biodiversidade nos (agro)sistemas" (COSTA NETO, in FLOEHLICH; DIESEL, 2009, p. 126).

No sentido da construção da sustentabilidade, observa-se que há um reconhecimento da importância dos pequenos agricultores. O manejo dos recursos naturais tem de: "[...] ser aplicado sob as condições altamente heterogêneas e diversas em que vivem os pequenos agricultores, além de ser ambientalmente sustentável e baseado na utilização dos recursos locais no conhecimento tradicional" (ALTIERI, 2012, p. 119).

Como a sustentabilidade está relacionada com a redução da agressão, tecnicamente quanto menor a propriedade mais propícia para que ela seja possível: "[...] Numa propriedade camponesa típica, o retorno de energia em relação ao trabalho empregado é suficientemente alto para garantir a manutenção do sistema" (ALTIERI, 2012, p. 122).

Os defensores da utilização do milho crioulo, como instrumento de sustentabilidade da propriedade, do ambiente e do social, ainda consideram os diversos aspectos relacionados, como a cultura, os conhecimentos acumulados, a prática agrícola voltada para a preservação do equilíbrio 
ambiental. Esse milho resulta do acúmulo de conhecimentos construídos e reconstruídos coletivamente de forma solidária: “[...] as sementes crioulas ou locais são aquelas melhoradas e adaptadas por agricultores, por seus próprios métodos e sistemas de manejo, desde que a agricultura se iniciou há mais de dez mil anos" (SANTILLI, 2009, p. 158).

No curso desse processo evolutivo, há uma condição importante que é da variabilidade genética presente no milho crioulo. Isso permite a manutenção das condições para a preservação da agrobiodiversidade:

Ao longo dos séculos, gerações de agricultores desenvolveram sistemas agrícolas complexos, diversificados e localmente adaptados. Com o passar do tempo, esses sistemas foram sendo manejados, testados e aprimorados por meio de práticas engenhosas, muitas vezes conseguindo garantir a segurança alimentar da comunidade e a conservação da biodiversidade e dos recursos naturais. (ALTIERI, 2012, p. 159).

A manutenção da biodiversidade somente é possível quando há sustentabilidade, pois no desequilíbrio socioambiental a probabilidade de preservação é drasticamente reduzida, pela ausência das condições indispensáveis para isso, como as condições ambientais, mas também os aspectos sociais e culturais. Portanto, as comunidades locais e tradicionais e as pequenas propriedades representam um Oasis no território do agronegócio:

[...] Esses microcosmos do patrimônio agrícola ainda podem ser encontrados em todo o mundo em desenvolvimento, abrangendo nada menos do que 10 milhões de hectares, proporcionando uma série de serviços culturais e ecológicos para as populações rurais, mas também para a humanidade, tais como a preservação das formas tradicionais de conhecimento agrícola, de raças e sementes crioulas e formas autóctones de organização sociocultural. (ALTIERI, 2012, p. 159).

Por outro lado, quando é utilizado o milho transgênico-além da questão da apropriação genética feita pelo patenteamento - por sua concepção é a maximização da produção. Nessa situação não são considerados os impactos ambientais e sociais decorrentes de uma agricultura capitalista e industrial, que causa impactos irreversíveis, esgotamento do solo e exclusão social.

$\mathrm{Na}$ atualidade o plantio de transgênicos domina a produção de milho no Brasil, principalmente nas grandes propriedades. A opção, normalmente, é para aumentar a produtividade; mas, há também dificuldades de obtenção de sementes não transgênicas no mercado, o que inviabiliza a intencionalidade dos que pretendem cultivar milho crioulo ou mesmo híbrido. 
Apesar do aumento da produção, pela ampliação das fronteiras agrícolas e a introdução das sementes transgênicas, sob a justificativa, que acabaria com a fome, isso não ocorreu:

E o pior: a alta produtividade das monoculturas não significou mais comida na mesa do brasileiro. A "modernização" determinou os rumos da pesquisa agropecuária, da assistência técnica e extensão rural e do credito rural, estreitamente vinculados e destinados a favorecer o agronegócio. Ela estimulou a mecanização, o uso intensivo de fertilizantes sintéticos e agrotóxicos e a utilização das variedades, raças e híbridos de alto rendimento e baixa diversidade genética. (SANTILLI, 2009, p. 87).

Mesmo com a prática hegemônica do cultivo de transgênicos o milho crioulo está presente em inúmeras experiências, as quais ainda não são visíveis, mas representam as condições de desenvolvimento sustentável nesses locais onde ocorre, constituindo-se em "territórios do milho crioulo", como é o exemplo do Município de Anchieta/SC:

Para se contrapor ao modelo que aí está, tínhamos convicção que uma coisa era certa, tínhamos que ter autonomia na produção, resgatar sementes crioulas, adubação verde, construir pequenas indústrias, e começamos o trabalho de base, colocando a situação financeira, e sobre as sementes de milho crioulo, como proposta inicial de nosso trabalho. (CANCI, 2002, p. 9).

Dessa iniciativa resultou na visualização de um território de resgate, melhoramento e cultivo de sementes crioulas, especialmente o milho, o qual tem assegurado a manutenção de um modelo de desenvolvimento sustentável, com preservação da biodiversidade, da cultura coletiva e solidária, da aplicação de práticas e de saberes tradicionais. Esse conjunto tem se mostrado como um diferencial naquele território, permitindo o equilíbrio ambiental, a independência e a autonomia econômica e social das famílias que fizeram essa opção.

A visão distinta acerca da opção pelas sementes - transgênicas ou crioulas - tem uma relação direta com a sustentabilidade, no entanto, tem ainda uma conotação relacionada com o tamanho da propriedade, pois as experiências com o milho crioulo normalmente ocorrem nas pequenas propriedades, com diferenças da proposta da agricultura industrial e capitalista:

Não resta dúvida que a formação da pequena propriedade nas áreas coloniais sulinas constituiu-se em experiência agrária ímpar e distinta no Brasil. Ela se desenvolveu especialmente a partir de meados do século XIX, contratando com o tradicional domínio do latifúndio que marcou sobremaneira o controle e uso da terra no país ao longo de séculos. (RADIN in ZARTH, 2012, p. 89). 
A conjugação de condições da pequena propriedade com o plantio de sementes crioulas fortalece as condições para um desenvolvimento sustentável. Essa possibilidade tem se demonstrado viável em diversas regiões do país. Porém, no presente ensaio serão tratadas apenas as situações da Região do Extremo Oeste de Santa Catarina, onde em vários municípios e feita a opção pelo plantio das sementes crioulas, por exemplo, em Anchieta e Guaraciaba.

$\mathrm{Na}$ Região Centro Serra do Rio Grande do Sul, também há experiências de produção de milho crioulo na pequena propriedade; no entanto, nem sempre tem a visibilidade adequada e necessária. Mesmo assim, especialmente no Município de Ibarama, muitos agricultores optam por um modelo alternativo de agricultura, como é o caso dos que plantam milho crioulo:

[...] grupo de agricultores familiares, formado por aproximadamente 30 famílias do município de Ibarama/RS, estimulados por extensionistas da Associação Rio-Grandense de Empreendimentos de Assistência Técnica e Extensão Rural (EMATER/RS ASCAR) passaram, a partir de 1998, a se organizar e desenvolver procedimentos de resgate, conservação e multiplicação de cultivares crioulas de milho além de outras culturas. (CASSOL, 2013, p. 14).

Evidentemente essa opção não é majoritária, mas não deixa de ser estratégica para o desenvolvimento local e regional. Em termo de extensão plantada com sementes crioulas: "atinge, na atualidade, em torno de 1.400 ha, cultivada por, aproximadamente, 650 famílias” (CASSOL, 2013, p. 14). Portanto, para o município isso representa uma parcela importante dos agricultores. Apesar da peculiaridade própria da região, notam-se semelhanças com outras experiências, as quais são desenvolvidas em diversas regiões do país, por exemplo:

Colonos, sitiantes, agregados, camaradas, posseiros, pequenos agricultores, meeiros, foreiros, caboclos, caipiras e sertanejos são as diversas denominações que perpassam a bibliografia que trata destes agricultores que, se não são de subsistência, desenvolvem uma agricultura com mão de obra familiar. (FERREIRA; BRANDENBURG, 1998, p. 96).

Pelo que se constata é possível afirmar que: “[...] a produção de cultivares crioulas ganha importância e vem conquistando cada vez mais agricultores, o que se reflete no aumento do estoque de sementes de cultivares crioulas para trocar e comercializar com agricultores do município e da região"(CASSOL, 2013, p. 15). Em virtude de a maior parte da população do município viver no meio rural e prevalecer no mesmo a 
pequena propriedade: "O milho crioulo é um dos produtos agrícolas de grande importância no município de Ibarama” (CASSOL, 2013, p. 55).

Essa constatação pode destoar do pensamento dominante, pois:

Em nome da "modernização" da agricultura tratou-se de classificar os agricultores em aptos e inaptos diante dos benefícios das mudanças ofertadas. A inaptidão é atributo de setores tidos como tradicionais, arcaicos, que resistem em manter e defender valores culturais, crenças e formas de organização antigas. (FERREIRA; BRANDENBURG, 1998, p. 37).

Porém, como ocorre em muitos outros lugares, o milho crioulo representa uma alternativa de manutenção das famílias no campo.

Essa opção - pelas sementes crioulas - é um sinal de resistência e não está presente apenas em possíveis "sonhadores ou idealistas”, mas encontra respaldo em organismos e organizações internacionais. Inclusive, há uma discussão de que as questões relacionadas com a produção de alimentos e da qualidade ambiental devem ser temas abordados como direitos humanos:

Em 1999 um estudo do Conselho Econômico e Social sobre o direito à alimentação, submetido à Comissão de Direitos Humanos da ONU 463, sustentou que os direitos dos agricultores deveriam ser tratados e promovidos como uma parte integrante do direito humano à alimentação, já que "o nosso futuro suprimento de comida, e a sua sustentabilidade, depende de que tais direitos (dos agricultores) sejam estabelecidos com firmeza". (SANTILLI, 2009, p. 300-301).

A partir daquele ano houve alguns avanços, principalmente em países com governos comprometidos com propostas de inclusão social e econômica, mas isso não ocorreu no Brasil. Assim, no país não há uma inclinação pela expansão do desenvolvimento sustentável; porém, isso não significa a inexistência de expectativas e experiências nessa direção. A problemática que envolve o desenvolvimento é complexa e longe de ser uma definição consensual; portanto, depende de amplos e produtivos debates. A seguir, algumas considerações sobre o tema na expectativa de contextualizar a sustentabilidade nos territórios do milho crioulo.

\section{Breves tessituras sobre a sustentabilidade}

Tratar do desenvolvimento enseja discorrer sobre um conjunto de medidas capazes de propiciar reflexões acerca do seu significado e dos interesses em cada compreensão do que ele é. Geralmente o desenvolvimento é visto apenas como sinônimo de crescimento econômico. Para esse modelo economicista é preciso o aumento constante do consumo, o que implica em crescente gasto de energia e de recursos naturais. Esse 
tipo de desenvolvimento normalmente não leva em consideração aspectos relacionados com as questões sociais, ambientais e culturais.

Portanto, quando não são considerados aspectos gerais no desenvolvimento - além do econômico -, ele não é sustentável, pois leva ao esgotamento dos recursos naturais, colocando em risco o futuro da humanidade. Contrapor-se a essa situação é uma questão estratégica para a qualidade de vida da atual e das futuras gerações, para isso é preciso compreender que: "Sucintamente, pensar, discutir e estabelecer ações de desenvolvimento territorial significa, num primeiro momento, ter uma compreensão renovada e crítica do território, da territorialidade e do desenvolvimento." (ALVES; CARRIJO; CANDIOTTO, 2008, p. 29).

O modelo de desenvolvimento considerado não sustentável privilegia as atividades econômicas, sem preocupações com as consequências. A situação tende a ser ainda mais preocupante quando as regras do desenvolvimento são estabelecidas por empresas multinacionais; afinal, nesses casos, a despreocupação com as questões sociais e ambientais tende a ser maior. Isso pode ameaçar, por exemplo, a diversidade biológica e a disponibilidade desses recursos comprometendo o próprio crescimento econômico.

Por sua vez, o desenvolvimento sustentável indica a necessidade de equilibrar o crescimento econômico com a preservação dos recursos naturais. Nessa concepção, preservar é também sinônimo de desenvolvimento, pois isso assegura longevidade aos processos que o sustentam.

A polêmica sobre o conceito de sustentabilidade se dá pelas diferentes concepções, por exemplo, há os que defendem o equilíbrio ambiental, com a preservação dos recursos naturais apenas com interesse no retorno econômico, em uma visão estreita da necessidade de preservação.

Por outro lado há os que defendem o equilíbrio ambiental com maior amplitude, colocando como parte o ser humano e suas atitudes frente ao ambiente, em processo de interação e respeito. Nessa concepção de desenvolvimento, com preservação, o ambiente não é apenas fonte de renda, mas a estrutura de sustentação vital para a manutenção da atual e das futuras gerações.

Evidentemente que não cabe ingenuidade nesse conflito, pois os interessantes são os mais diversos e muitos poderosos, mas é preciso acreditar que existem grupos de pessoas - de todas as profissões e posições políticas, ideológicas e religiosas - que pensam em um equilíbrio ambiental sem a expectativa de obter alguma vantagem individual, portanto, colocam o coletivo acima dos seus próprios interesses. É nessa direção que se pretende discutir a sustentabilidade no presente ensaio, sendo que a condição 
necessária está relacionada com a agricultura, especialmente no território do milho crioulo, como acontece nos Municípios de Anchieta/SC e de Ibarama/RS.

Geralmente a agricultura é uma atividade agressiva ao ambiente, tendo em vista a necessidade de ocupar espaços anteriormente protegidos por vegetação nativa. Também a agricultura - em decorrência do modelo adotado - pode não ser capaz de oferecer um retorno social adequado aos interesses da maioria da população brasileira, especialmente os mais pobres. Isso ocorre, por exemplo, com o agronegócio, modelo agrícola voltado para a produção de commodities. Nesse modelo, a produção agrícola é vista apenas como meio de obtenção de ganhos financeiros.

Essa condição de exploração financeira é uma realidade no Brasil, desde a chegada dos portugueses que utilizaram as terras da colônia, como se ela estivesse vazia - inclusive de pessoas, portanto, poderia ser usada de acordo com os interesses externos ao espaço da metrópole:

A política econômica desenvolvida pela metrópole a partir de então se fixava na produção agrícola e mineral, voltada para o mercado europeu. Porém, neste período, o Rio Grande do Sul não se encaixava nas prioridades de comércio, agricultura e nem na atividade mineradora e, portanto, não era de interesse da Coroa integrá-lo ao sistema colonial. (LOSEKANN, 2011, p. 40).

Também sobre o conceito de sustentabilidade, muitas poderiam ser as possibilidades de definição, mas é preciso optar por uma, a qual se entende mais abrangente, mas que seja suficiente para respaldar o conjunto de ações inerentes ao processo de preservação dos recursos naturais, sem descuidar de incluir as pessoas nesse debate, de acordo com Belik (2003), a sustentabilidade incorpora conceitos ligados à preservação do meio ambiente, indicando a contrariedade da utilização de agrotóxicos, bem como da produção extensiva em monoculturas. Também, os defensores da sustentabilidade, por exemplo, colocam-se frontalmente contra o uso de produtos e alimentos transgênicos.

Os motivos dessa postura são os mais diversos, mas há um elemento central posto no debate, trata-se da autonomia do agricultor - sementes próprias e independência na sua utilização. Para isso, é indispensável à preservação das sementes crioulas, pois somente elas possuem um amplo espectro genético, capaz de corresponder às expectativas de continuar produzindo, mesmo no rompimento com o pacote tecnológico do agronegócio para a agricultura.

Nessa agricultura, denominada de camponesa, é identificável uma perspectiva diferenciada na sua relação com a natureza, pois mesmo 
sabendo que não há como produzir alimentos sem agressão ambiental, alguns agricultores buscam mecanismos que podem minimizar os impactos. Isso pode ocorrer por meio de diversas práticas, como: produzir respeitando as condições solo; evitar a expansão desnecessária da fronteira agrícola; agricultura agroecológica; e outros. Com isso, é possível reduzir significativamente os impactos de poluição do solo, da água e do ar:

Somente nas últimas décadas, é que os problemas decorrentes da agricultura convencional se tornavam visíveis, para a opinião pública. A poluição da água, a degradação dos solos, a má qualidade dos alimentos, a diminuição da biodiversidade e o êxodo rural fazem com que a agricultura orgânica se imponha cada vez mais como alternativa indispensável. (JESUS, in AQUINO; ASSIS, 2005, p. 13).

No entanto, esse modelo agrícola, sem agroquímicos - mesmo tendo sido usado majoritariamente até a revolução verde -, é considerado ultrapassado e incapaz de garantir a produção de alimentos para a humanidade. Portanto, quem opta pela agricultura com menor impacto sofre de diversas formas, seja pela pressão do agronegócio, pela falta de incentivos governamentais e institucionais, portanto: "O processo de abandono desse grupo de agricultores é reconhecido por pesquisadores, mas asseveram a contribuição dos mesmos aos aspectos do desenvolvimento sustentável e da biodiversidade" (CAMPOS, 2007, p. 59).

Mesmo não sendo visíveis perante o modelo hegemônico de agricultura, os agricultores camponeses e os que produzem de forma agroecológica têm importante contribuição para o desenvolvimento sustentável, apresentando-se como alternativa de produção agrícola:

Tais exemplos revelam que houve formas de grupos humanos se relacionarem menos predatoriamente com seu ambiente, e que tais formas de relacionamento podem ser reaproveitadas e aprimoradas. $\mathrm{O}$ desafio da atualidade consiste em recuperar padróes ecologicamente superiores a aprimorá-los à luz do conhecimento hoje disponível. (KHATOUNIAN, 2001, p. 19).

Não há como negar - nem é essa intenção - que a tecnologização da agricultura elevou a produtividade. Também é preciso reconhecer que isso implicou em aumento de exportação, resultando na entrada de divisas no país. No entanto, a fome e a miséria continuam flagelando uma parcela do povo brasileiro, esse é um sinal que esse modelo de desenvolvimento da agricultura não foi suficiente para amenizar tais problemas sociais do Brasil. Isso se constata mesmo com a expansão da fronteira agrícola e a destruição de biomas estratégicos para o futuro, como é o Cerrado e a Floresta Amazônica. 
Portanto, desenvolvimento sustentável é sinônimo de preocupação com as questões ambientais e sociais envolvidas. É por isso que ele somente é possível, quando a agricultura mantém suas características originarias, que sempre foram no sentido de garantir a produção de alimentos, sem agroquímicos e não apenas para obtenção de lucro. Para muitos pesquisadores, isso somente seria possível nos projetos das pequenas propriedades: “[...] A agricultura familiar é fundamental para a segurança alimentar, a geração de emprego e renda e o desenvolvimento local em bases sustentáveis e equitativas" (SANTILLI, 2009, 87).

Isso ocorre porque nessas propriedades - normalmente - a maior preocupação é com a produção de alimentos de qualidade, ficando em segundo plano a obtenção de vantagens financeiras, mesmo que isso não possa ser ignorado. Se fosse, colocaria em risco a própria continuidade da proposta, já que não é possível fugir de algumas relações com o capital. Portanto, o agricultor precisará de recursos financeiros para manter a sua propriedade.

O posicionamento majoritário que prega a inviabilidade da pequena propriedade ou da produção com saberes e práticas tradicionais encontra resistências dos próprios agricultores, o que é respaldado na comunidade científica: "[...] as unidades familiares são mais produtivas e sustentáveis, do ponto de vista socioambiental, além de serem economicamente viáveis. Destaca, ainda, que todos os países desenvolvidos tiveram na agricultura familiar um sustentáculo do seu dinamismo econômico e de uma equilibrada distribuição das riquezas" (SANTILLI, 2009, p. 86).

A expressão a seguir corrobora com esse entendimento: "O reconhecimento da diversidade de agricultores e recursos disponíveis como balizador de políticas e estratégias de desenvolvimento tem se fortalecido com o advento do debate sobre a agricultura sustentável" (FERREIRA; BRANDENBURG, 1998, p. 36). Também é preciso tratar a questão da sustentabilidade e da segurança alimentar, a partir de consensos: "O desafio de fazer confluir para o mesmo rumo os objetivos da segurança alimentar e da sustentabilidade na agricultura guarda enorme possibilidade de resolução quando pensadas as práticas de encontro e harmonia, entre diferentes atores sociais envolvidos com os dois temas" (FERREIRA; BRANDENBURG, 1998, p. 309).

No entanto, essa proposta de agricultura comprometida com a produção de alimentos tem encontrado fortes resistências no Brasil em razão da falta de políticas e de investimentos públicos e, quando estes existem, inúmeras barreiras são impostas aos agricultores camponeses. Também a legislação protetiva ao agronegócio impõe restrição à comercialização de sementes, por exemplo. 
A legislação brasileira tem ser preocupado mais com a proteção na produção de commodities para a exportação do que com a produção de alimentos para a população. Isso nega direitos fundamentais aos agricultores camponeses, por exemplo, os que melhoram e cultivam suas próprias sementes: “[...] As leis de sementes não apenas produzem seus efeitos sobre os sistemas agrícolas como também têm interfaces com as políticas de desenvolvimento rural sustentável, segurança alimentar e nutricional, inclusão social, agrobiodiversidade e sobrevivência cultural dos povos tradicionais" (SANTILLI, 2009, p. 133).

Diante desse quadro, de negativa de direitos, é necessária uma atenção em relação a esses agricultores, para que eles continuem cumprindo o papel estratégico de conservar e melhorar o germoplasma que garante a produção de alimentos no país e das próprias melhorias artificiais das sementes: "Tal direito deve ser compreendido de forma ampla e inclusiva e abarcar quaisquer decisões políticas que produzam impactos sobre os sistemas agrícolas locais e os recursos fitogenéticos para alimentação e agricultura" (SANTILLI, 2009, p. 345).

A situação se apresenta envolta em conflitos, resultante da disputa de poder no território; porém, muitas outras disputas poderiam ser acrescidas, como a discussão da viabilidade econômica, o financiamento adequado de projetos alternativos, pois decorrem da tensa convivência entre os diferentes atores que agem no território do milho crioulo:

Neste sentido, é possível então afirmar que as questões e os conflitos de interesse surgem das relações sociais e se territorializam, ou seja, materializam-se em disputas entre esses grupos e classes sociais para organizar o território da maneira mais adequada aos objetivos de cada um, ou seja, do modo mais adequado aos seus interesses. (CASTRO, 2005, p. 41).

A intencionalidade em demonstrar o quanto é preciso refletir sobre as questões relacionadas com o desenvolvimento sustentável e a agricultura é, ao mesmo, tempo desafiadora e gratificante, especialmente pela possibilidade de tornar visível a experiência de agricultores simples, mas que demonstram grande conhecimento e preocupação com a sustentabilidade social e ambiental.

Quando se trata do desenvolvimento sustentável, existem diferentes visões; no entanto, a proposição da Comissão Mundial sobre Meio Ambiente e Desenvolvimento, criada pelas Nações Unidas para discutir e propor meios de harmonizar as questões do desenvolvimento econômico e da conservação ambiental parece ser a mais adequada. Assim, o desenvolvimento sustentável é capaz de suprir as necessidades da geração atual, sem comprometer a capacidade de atender às necessidades das futuras 
gerações. Portanto, é o desenvolvimento que não esgota os recursos naturais, preservando-os para o uso futuro. No item seguinte, será apresentada uma reflexão ao desenvolvimento sustentável e a produção de milho crioulo no Município Anchieta/SC.

\section{O território do milho crioulo em Anchieta - em busca de sustentabilidade}

Anchieta é um município localizado no Extremo Oeste de Santa Catarina, de acordo com dados do censo demográfico do IBGE/2010, conta com pouco mais de cinco mil habitantes. Também, de acordo com a mesma fonte, $59,5 \%$ da população vive no campo.

O município possui uma superfície acidentada, dificultando, em muitas propriedades a mecanização. Evidentemente que não apenas por motivos das condições do terreno, mas também pela compreensão de muitos agricultores, em boa parte das propriedades é plantado o milho crioulo, além de outras variedades crioulas. Essa prática facilita o desenvolvimento da agricultura agroecológica, potencializando o desenvolvimento sustentável.

Nesse modelo, que se apresenta como alternativa ao agronegócio há um posicionamento da comunidade com olhares para o coletivo, potencializando as práticas solidárias e cooperativas, segundo Ferreira e Brandenburg (1998, p. 100): “As noções de comunidade, construídas a partir de diferentes contextos, ressaltam a ideia da solidariedade, de espaço social, de modo de vida, de pertencimento". Isso não significa que as propriedades não sejam viáveis economicamente, bem como, ofereçam condições dignas aos seus proprietários, esse modelo não é majoritário, mas identificado em muitas regiões. No entanto:

[...] Destaca-se a capacidade de produção e de organização das comunidades que se formavam nessas regiões. Por isso foi referência por décadas, inclusive nas regiões alcançadas pelos processos migratórios subsequentes, como foi o caso do Norte do Rio Grande do Sul, do Oeste de Santa Catarina e Sudoeste do Paraná. Ser colono passara a ser sinônimo, entre outros, de garantia que o indivíduo supria com facilidade suas necessidades e de que vivia com dignidade. A agricultura que praticava lhe possibilitava cera autonomia, pois, em geral, produzia suas próprias sementes e não dependia de insumos. (RADIN in ZARTH, 2012, p. 78).

Foi nesse cenário que o milho crioulo assumiu protagonismo em muitas propriedades, pois é reconhecida a importância da variabilidade genética do milho crioulo para o desenvolvimento da agricultura, principalmente sustentável, a qual ocorre geralmente nas pequenas propriedades rurais, como explica a pesquisadora do Núcleo de Estudos 
em Agrobiodiversidade da Universidade Federal de Santa Catarina, Juliana Bernardi Ogliari (2007, p. 191):

Variedades locais autóctones, cultivadas por pequenos produtores ao longo de muitos anos, têm sido especialmente destacadas como valiosas fontes de características desejáveis. Podem ser definidas como populações cultivadas, distintas geograficamente ou ecologicamente, diversas em sua composição genética, bem como adaptadas á condição agro-climática local.

A autora reconhece as condições diferenciadas sobre a produção de milho no Extremo Oeste de Santa Catarina, com forte tendência de entrosamento entre os pequenos agricultores:

O sistema de produção agrícola da Região SuldoPaís,particularmente, no município de Anchieta-SC, está baseado na unidade de produção familiar, onde ainda é possível encontrar variedades locais de muitas espécies. Entre 1998 e 2002, 33 variedades locais de milho foram identificadas pelo Sindicato dos Trabalhadores na Agricultura Familiar (SINTRAF), sendo 14 cultivadas em Anchieta há mais de dez anos. (OGLIARI, 2007, p. 192).

O engajamento pela agricultura alternativa, com a utilização de sementes crioulas, atinge as pessoas, as comunidades e também as instituições, como é o caso da Igreja Católica, que incentiva os agricultores na sua caminhada. $\mathrm{O}$ sindicato dos trabalhadores rurais e uma associação organizada pelos agricultores ajudam a motivar os produtores de milho crioulo no município e, também, há parcerias com o próprio Município de Anchieta, a Universidade Federal de Santa Catarina, a Epagri e outras instituições que apóiam os agricultores que cultivam o milho crioulo:

No Oeste Catarinense vem sendo desenvolvido um trabalho para resgate, conservação e produção de várias espécies cultivadas através do incentivo de ONGs (Centro Vianei de Educação Popular, Associação de Pequenos Agricultores do Oeste Catarinense (Apaco), dos Movimentos Sociais, do Centro de Apoio ao Pequeno Agricultor Familiar (CAPA III), do Sindicato dos Trabalhadores na Agricultura Familiar de Anchieta (Sintraf/ Anchieta) e a da Associação dos Pequenos Agricultores Produtores de Milho Crioulo Orgânico e Derivados. (ASSO) (CANCI; VOGT; CANCI, 2002, p. 71).

Reconhecendo as contribuições do Município de Anchieta na conservação do milho crioulo, no ano 2000, através da Lei no 11.455/2.000, consolidada pela Lei $n^{\circ} 16.722 / 2015$, do Estado de Santa Catarina, o município recebeu o título de "Capital Catarinense do Milho Crioulo." Esse reconhecimento não é apenas político, porque pesquisas constatam a 
contribuição: "O Extremo Oeste de Santa Catarina (EOSC) caracterizase pela diversidade de variedades selecionadas e mantidas por agricultores familiares ao longo das gerações" (VIDAL, 2015, p. 34).

Essa postura dos agricultores tem origem na própria colonização do local, por volta dos anos de 1950, quando ainda os cultivos de milhos se baseavam principalmente em sementes produzidas pelos agricultores, com a prática da agricultura tradicional. Isso permite a conservação não apenas das sementes, mas também dos saberes e práticas:

A conservação da agrobiodiversidade e dos conhecimentos associados são críticos para manter os sistemas tradicionais de produção familiar. Como resposta de resistência, a região concentra uma intensiva articulação impulsionada por organizações sociais junto aos agricultores familiares para a recuperação, conservação da diversidade genética e cultural. (VIDAL, 2015, p. 35).

Segundo Vidal (2015), foram identificadas na região do Extremo Oeste, 1.513 populações de variedades locais de milho, dentre as quais 1.078 eram variedades de milho pipoca, 337 de milho comum, 61 de milho doce/adocicado e 37 de milho farináceo. Isso demonstra a diversidade de populações locais de milho, bem como as redes sociais de sementes e a distribuição geográfica de todas as populações locais de milho.

Uma instituição que tem sido parceira dos agricultores no desenvolvimento de suas propostas é a Universidade Federal de Santa Catarina (UFSC), que tem atuado de forma relevante na Região do Extremo Oeste de Santa Catarina, através do Núcleo de Estudos em Agrobiodiversidade, com pesquisas para a visualização e mensuração da importância da região nos estudos sobre as sementes crioulas, especialmente o milho. Nos territórios do milho crioulo, ele exerce/recebe influências não apenas da lavoura e da sua carga genética, mas está diretamente imbricado com aspectos organizacionais, sociais, econômicos e políticos:

Particularmente, com relação às variedades locais, tradicionais ou crioulas de milho, elas carregam consigo valores culturais importantes por participarem de tradições e heranças familiares, fatos históricos locais, cerimônias religiosas e receitas culinárias especiais, além de desempenharem importante papel social em diversas regiões do Brasil. (COSTA, 2013, p. 35).

$\mathrm{Na}$ organização e na atuação desses agricultores, é visível a busca constante por melhorias das sementes crioulas. No entanto, isso não é feito de forma isolada ou privada. É disponibilizado o acesso a esse debate para todos, pois para os agricultores a importância das sementes crioulas vai além da produção, articulando-se com a garantia da subsistência pessoal e familiar, contribuindo na produção de alimentos de qualidade e valorizando 
os saberes locais. Conhecimento local é "[...] uma determinada construção social e cultural orientada para a criação de identidade, do sentimento de mantença e de reprodução de um grupo, em particular, que está inserido e contextualizado num determinado espaço geográfico" (WACHOWICZ, 2013, p. 229).

Essa proposição dos que defendem o milho crioulo tem também uma preocupação com a autonomia dos agricultores, que têm por meta garantir o direito de manter as sementes sob o seu controle, bem como assegurar a possibilidade da troca e da comercialização das sementes, sem restrições isso não significa que não tenha qualidade - como ocorre atualmente com a lei de proteção aos cultivares no Brasil.

Nessa proposta defendida pelos agricultores - da produção agrícola alternativa -, é preciso que as sementes sejam livres de patentes, pois somente assim seria possível adquirir independência, aproveitando os conhecimentos que estão à "mão do agricultor" para construir alternativas de melhorias na qualidade das sementes e da produtividade: "A semente crioula é a semente da nação soberana, o agricultor com tecnologia sim, mas aonde ele próprio ou juntamente com a pesquisa pública e séria é a matriz" (CANCI, 2002, p. 21). Dessa forma, seria possível garantir a produção de alimentos na qualidade, na quantidade e nos preços compatíveis com a realidade dos consumidores.

Para Santilli (2009, p. 142-143): “Os sistemas locais são amplamente predominantes dos países em desenvolvimento, especialmente para algumas espécies agrícolas utilizadas na alimentação local. Estima-se que 1,4 bilhão de pessoas vivem em famílias de agricultores que usam suas próprias sementes". Essas preocupações, com Segurança Alimentar e da Soberania Alimentar, contrapõem-se aos argumentos da agricultura industrial e capitalista. Assim, configura-se o conflito entre os modelos de agricultura camponesa e agroecológica, com o do agronegócio.

$\mathrm{Na}$ proposta camponesa de agricultura, é possível afirmar que: "Mesmo que essas pessoas desempenhassem suas atividades agropecuárias de maneira individualizada, o modo de pensar e de agir se assemelhava com o dos caboclos e dos nativos" (MOREIRA, 2013, p. 57). No entanto, essa proposta enfrenta gigantesca oposição pelo modelo hegemônico, impossibilitando inclusive sua visibilidade como alternativa de produção de alimentos.

No item seguinte, pretende-se demonstrar uma experiência parecida no Município de Ibarama, no Estado do Rio Grande do Sul. Mesmo com poucas informações trocadas entre as duas realidades, é possível encontrar pontos de convergência entre eles, o que se demonstrará a seguir. 


\section{O território do milho crioulo em Ibarama - em busca de sustentabilidade}

A visão de sustentabilidade percebida entre os agricultores do território do milho crioulo de Ibarama considera a necessidade de preservar para que se tenha um equilíbrio ambiental não apenas para a exploração econômica, mas voltada para a preservação considere a manutenção dos recursos naturais, com respeito aos aspectos sociais e culturais.

Nesse sentido, há elementos que devem ser considerados como indispensáveis para que se caracterize esse modelo de sustentabilidade, como a preservação da diversidade biológica, que permite manter a produção de cultivares crioulos, com atenção especial aos agricultores que as mantêm:

Do ponto de vista da conservação da agrobiodiversidade, e dos sistemas agrícolas locais, tradicionais e agroecológicos, é absolutamente fundamental assegurar os direitos dos agricultores de guardar, usar, trocar e vender as sementes (em mercados locais), tanto de variedades locais como de protegidas. (SANTILLI, 2009, p.311).

Tendo em vista a complexa realidade de preservar a agrobiodiversidade, é necessária uma reflexão mais atenta. Sem isso, não há como realizar o desenvolvimento, mesmo o não sustentável, visto que, sem o potencial genético inicial, a alta tecnologia não se sustenta. Então, preservar a agrobiodiversidade não é apenas um ato em defesa do desenvolvimento sustentável, mas uma contribuição para a continuidade da vida no Planeta e da evolução da capacidade produtiva.

Esse processo ocorre em Ibarama/RS, nas propriedades que cultivam milho crioulo, caracterizando territórios de desenvolvimento sustentável: "No município de Ibarama, o milho cultivado em sua quase totalidade destina-se ao uso na propriedade e representa uma das principais culturas, com área de 3.500 ha” (CASSOL, 2013, p. 45).

No entanto, não são todos os agricultores que cultivam o milho crioulo. Então, constituem-se os territórios - alguns destinados ao agronegócio - que podem desenvolver a agricultura comercial e capitalista, desterritorializando saberes e práticas tradicionais, excluindo a diversidade biológica: "Os novos territórios estão sendo formados e transformados em todas as partes sobre os escombros das desterriotirialidades, da luta de classes ou das novas fontes especializadas de produção de mercadorias" (SANTOS; SOUZA; SILVEIRA, 1998, p. 273).

Analisar os modelos de agricultura é fundamental para externar as divergências sobre a sustentabilidade, pois não há de se esperar do agronegócio, complacência com a natureza, em razão da sua concepção, que 
tem por objeto exclusivamente a produção de commodities para a exportação, sem voltar olhares para a população que passa fome, por exemplo.

Essa condição, da agricultura, favorável ao modelo exportador, teve seu início com a ocupação branca, especialmente dos portugueses que aqui chegaram apenas para retirar da terra as riquezas e mandar para a metrópole. A agricultura brasileira foi organizada, “[...] desde passado distante, com o objetivo de fornecer produtos tropicais que interessavam ao mercado internacional. No período colonial, as terras eram doadas pelo rei de Portugal para exploração de cana-de-açúcar, primeiro produto agrícola cultivado" (FABRINI; ROOS, 2014, p. 13).

Esse modelo predatório de "distribuir" a terra para os já privilegiados e, por consequência, incentivar a agricultura também predatória, representada - em tempos recentes -, inicialmente pela "revolução verde" e na atualidade pelo agronegócio, enfrenta o contraponto de um projeto agrícola diferenciado. Essa proposta aqui denominada como "agricultura camponesa” normalmente é agroecológica e possui concepção de produzir com menores impactos e para a subsistência:

O "modo" caboclo parece apresentar uma incapacidade estrutural de afirmação no mercado moderno, mas mostra, em contrapartida, uma capacidade eficaz de indicar caminhos inovadores (equilíbrio com o ecossistema, por exemplo) para a agricultura familiar e capacidade de dar sustentação política pelo discurso, pela afirmação das diferenças e pela presença constante e perseverante nas ações empreendidas pelas lutas sociais, especialmente a da terra. (FERREIRA; BRANDENBURG, 1998, p. 77).

Mesmo que se defenda a agricultura tradicional, é importante compreender que nela também ocorrem avanços. No entanto, é preciso cautela, para não justificar a utilização de sementes transgênicas e de agroquímicos como sinônimo de melhoria. Também, nem sempre o avanço na agricultura significa a melhoria das condições de vida dos agricultores: “[...] a modernização ocorreu de maneira parcial, atingindo apenas alguns produtos, em algumas regiões, beneficiando alguns produtores e algumas fases do ciclo produtivo" (CASSOL, 2013, p. 23).

Essa desigualdade provocou uma "explosão" do êxodo rural no Brasil e, em pouco mais de meio século, houve uma completa inversão na localização das pessoas, chegando ao momento atual com pouco mais de $10 \%$ de pessoas no campo. Até meados do século passado, a população brasileira estava quase $80 \%$ no meio rural.

Porém, a distribuição populacional de Ibarama é diferenciada acerca da média brasileira de pessoas que vivem no campo, pelos dados de 2010: “[...] Ibarama localiza-se na região Centro Serra do Rio Grande do Sul, em uma área de $193 \mathrm{~km}^{2}$ e população de 4.371 habitantes, dos quais 3.318 
vivem no meio rural" (OLIVEIRA, 2015, p. 2). Poderia ser considerada a contribuição das sementes crioulas para a manutenção desse índice de pessoas que permanecem no campo? Seria pretensiosa a afirmação positiva; no entanto, é uma possibilidade que precisa ser considerada, inclusive para não acreditar que essa permanência no campo é uma mera coincidência.

Para ilustrar esse indicativo, é interessante observar os motivos que levam os agricultores a optar pelo cultivo de sementes crioulas: "Adicionalmente, a partir desta experiência, o uso de sementes de cultivares crioulas possibilitou às famílias reduzir os custos de suas lavouras, diminuir significativamente o uso de agroquímicos e aumentar a renda por meio da troca e comercialização com outros produtores rurais" (OLIVEIRA, 2015, p. 5).

Evidentemente que deixaram o campo, os pequenos agricultores, pobres - normalmente os que utilizavam saberes e práticas tradicionais -, contribuindo para a erosão, não apenas dos saberes, mas também diversidade biológica, pois o modelo agrícola que se estabeleceu nesse espaço, tem caráter genético reducionista, impondo apenas seres vivos melhorados geneticamente, com estreita variabilidade de genes, relegando os demais, inclusive aqueles que lhe deram origem: "Assim, o processo de modernização levou um grande número de agricultores a uma degradação social e econômica" (CASSOL, 2013, p. 23).

Destaca-se que, embora tenha ocorrido recentemente forte êxodo rural, a proposição de fomentar com maior ênfase a agricultura para a exportação, sempre esteve presente na agricultura brasileira, a qual inicia com doação das terras brasileira aos "amigos do rei": "Neste contexto, inicia o monopólio da apropriação da terra com a propriedade fundiária regulada pela Lei das Sesmarias, cuja posse era permitida somente a uns poucos: àqueles que dispunham de escravos, sendo o direito à terra proporcional ao número de escravos que cada um possuía" (FABRINI; ROOS, 2014, p. 13).

$\mathrm{O}$ argumento utilizado pelos defensores da agricultura capitalista e industrial é de que sem vantagens financeiras não há motivo para que exista, mesmo que para isso seja necessário sacrificar a natureza: “[...] a agricultura precisou reestruturar-se para elevar sua produtividade, não importando a degradação dos recursos naturais" (CASSOL, 2013, p. 24). Ocorre que a modernização da agricultura não foi capaz de oferecer alento aos agricultores pobres. Ao contrário, quanto mais avança a modernização da agricultura, maior a degradação ambiental e a exclusão social no campo em especial desses agricultores sem condições de adquirir o pacote tecnológico.

Da mesma forma que o avanço tecnológico provoca a exclusão dos agricultores pobres que não conseguem ter acesso ao pacote tecnológico, com a mecanização ocorre a expansão da fronteira agrícola, situação que também afeta os recursos naturais pela utilização dos recursos ambientais 
de forma predatória: "A exploração ambiental está diretamente ligada ao avanço do complexo desenvolvimento tecnológico, científico e econômico que, muitas vezes, altera de modo irreversível o cenário do meio ambiente e contribui para processos degenerativos da natureza" (CASSOL, 2013, p. 24).

É nesse contexto que são indispensáveis as reflexões acerca da sustentabilidade, pois dela depende a continuidade da atividade agrícola e do equilíbrio ambiental indispensável à qualidade de vida das pessoas. Portanto, um modelo agrícola voltado apenas para a obtenção de vantagens financeiras não atende a essas expectativas, sendo necessário reavaliar as alternativas que são apresentadas, por exemplo, a produção com sementes crioulas, a qual é estruturada em outros patamares técnicos, ambientais e sociais, tendo como objeto principal a produção de alimentos, com menores impactos ambientais: "[...] a agricultura deve ser enfocada sob um olhar que não se volte apenas para a reprodução do capital e sim para a busca de técnicas sustentáveis de produção que possa levar os agricultores familiares à reconstrução de sua autonomia" (CASSOL, 2013, p. 25).

Para Cassol (2013), os efeitos ambientais gerados pelo crescimento econômico foram considerados externalidades negativas do processo de expansão da economia, ou seja, não atende às expectativas de uma agricultura sustentável. Portanto, se a agricultura agride o ambiente com menor ou maior potencial - é indispensável à reflexão de como é possível amenizar esses impactos. Notadamente, quanto mais avançados tecnologicamente os pacotes da agricultura, maior a probabilidade de provocar agressões ao ambiente.

Do ponto de vista dos efeitos da sustentabilidade, é importante observar que ele está ligado com a durabilidade dos processos produtivos, seja do solo, da água ou da genética presente nas sementes: "A noção de sustentabilidade na agricultura está, então, diretamente associada à possibilidade de se manter a produção ao longo do tempo, conservando ou melhorando a base dos recursos produtivos" (CASSOL, 2013, p. 27).

A respeito dessa condição da durabilidade dos processos produtivos em um mesmo espaço, ela somente é possível com uma proposta que seja capaz de respeitar os limites ambientais dos elementos abióticos envolvidos e também do lastro genético das sementes: "Em relação ao conceito de agricultura sustentável, identificam-se três níveis: o primeiro é o desenvolvimento sustentável em geral; o segundo é o uso sustentável dos recursos naturais; e o terceiro é a agricultura sustentável propriamente dita, como um aspecto particular do uso dos recursos" (CASSOL, 2013, p. 43).

Para Cassol (2013), as dificuldades enfrentadas por muitas famílias para garantir a sua produção a partir dessa matriz produtiva sustentável estimularam a busca de opções de diversificação. É nessa lógica que se abre 
espaço para o cultivo de milho crioulo, feijão, legumes, verduras e frutas; portanto, uma diversificação na produção que permite na propriedade a rotatividade de culturas, favorecendo a manutenção da fertilidade do solo, dessa forma, segundo Cassol (2013, p. 42): "A agricultura familiar se constituiu em uma importante força principalmente nos espaços onde foram assentados os colonos europeus, como é o caso do município de Ibarama”.

Com o passar do tempo, a agricultura foi sendo transformada, atendendo especialmente aos interesses do agronegócio, com reflexos na prática agrícola, antes considerada como produtora de alimentos, agora transformada em mercadoria, onde os agricultores perdem o seu status de produtor e transforma-se em consumidor do pacote tecnológico.

Com o processo de "modernização" da agricultura, intensifica-se a utilização de produtos químicos e a mecanização da terra. Aliado a esses fatores, tem início o processo de formação de monopólios e a introdução de registros de patentes biológicas, com o lançamento das "sementes melhoradas" no mercado agrícola. As cultivares de sementes melhoradas são criadas para responder aos pacotes tecnológicos, com lastro genético pequeno, tendo a necessidade de aprimoramento constante mediante hibridação e/ou transgenia; portanto, não pode ser feita pelos agricultores.

Contrapondo-se a essas formas de produção, vinculadas ao capital, os agricultores familiares de Ibarama, município localizado na região CentroSerra do estado do Rio Grande do Sul, vêm, há muitos anos, trabalhando com o resgate e a conservação de sementes de milho crioulo. Essas sementes, chamadas de crioulas, são definidas como material cultivado localmente, geração após geração, sem a intervenção de mecanismos tecnológicos.

O milho crioulo é um dos produtos agrícolas de grande importância no município de Ibarama, e os agricultores, mesmo pressionados a comprar sementes, ano após ano, resistem e produzem as suas próprias sementes, livrando-se da dependência.

Muitos agricultores camponeses reconhecem à ameaça que as sementes híbridas e/ou transgênicas podem trazer ao meio ambiente e à saúde humana. Assim, a prática de cultivar sementes crioulas, classificálas e armazená-las de um ano para o outro faz parte da cultura de muitos agricultores familiares de Ibarama que procuram romper com o sistema de produção agrícola convencional, resistindo às pressões das grandes empresas sementeiras e defendendo uma proposta alternativa de desenvolvimento, com vistas à sustentabilidade ambiental, econômica e social (CASSOL, 2013). Eles preparam suas próprias sementes e as melhoram de acordo com sua necessidade e interesse.

Esse hábito de guardar sementes, em grande medida, vincula-se à tradição familiar, ou seja, as sementes são passadas de pai para filho, como 
uma herança, um patrimônio. As chamadas "sementes de vida" por Campos (2007) estão nas mãos dos pequenos agricultores há muitas décadas. E desse modo esses agricultores reconstroem conhecimentos diariamente ao plantar, replantar, classificar e armazenar essas sementes. Além disso, essas práticas transformam e criam novos territórios, assentados na luta contra o sistema hegemônico de produção de alimentos.

As práticas alternativas de produção como a da preservação de sementes crioulas divergem diretamente do modelo de modernização imposto pela agricultura capitalista e contribuem diretamente para a promoção do desenvolvimento local e de uma agricultura sustentável. E, deste modo, pode-se inferir que os agricultores camponeses de Ibarama, através do seu trabalho de resgate, cultivo, conservação e melhoria das sementes de milho crioulo, estão trabalhando para a construção de um novo território. Um território, que pretende ser livre das ameaças do sistema capitalista hegemônico, representado pelo agronegócio.

As sementes de milho crioulo representam, para os agricultores familiares de Ibarama, a manutenção da vida na terra, e assim, seguem firmes em seu trabalho, buscando desprender-se das relações impostas pelo sistema capitalista de produção, afirmando-se na busca de uma relação respeitosa e saudável com a natureza. Além disso, é possível observar, no trabalho cotidiano desses agricultores, que há uma aprendizagem junto com a natureza daqueles que cultivam a terra guardando seus saberes.

As estimativas indicam que aproximadamente $50 \%$ dos agricultores do município de Ibarama utilizam nas suas propriedades sementes crioulas: "Ressalta-se, portanto, que a agricultura familiar é o carro-chefe da economia neste município, e conta, principalmente, com a produção de alimentos de subsistência, o que garante a manutenção da vida no meio rural" (CASSOL, 2013, p. 46). Também há no município uma interessante prática, que pode ser considerada pedagógica, de incentivar - nas escolas - a discussão sobre as sementes crioulas. Com isso, há uma indicação da procura permanente por alternativas para a produção de base agroecológica, que recebe cada vez mais valorização na busca por um equilíbrio socioambiental.

A agricultura familiar e camponesa representa a possibilidade de reforçar iniciativas de revalorização dos territórios rurais: “[...] as práticas alternativas de produção como a preservação de sementes crioulas divergem diretamente do modelo de modernização imposto pela agricultura capitalista e contribuem diretamente para a promoção do desenvolvimento local e de uma agricultura sustentável" (CASSOL, 2013, p. 31).

Esse enfrentamento entre os modelos de produção agrícola (agronegócio $\mathrm{X}$ agricultura camponesa) se dá; mas, para muitos que defendem o agronegócio, a propriedade privada no Brasil é inabalável. Portanto, foge ao alcance do controle social ou estatal: “[...] Assim, a 
propriedade privada capitalista se ergue como uma instituição sagrada que não deverá ser ameaçada/desestabilizada, condição necessária para expansão e fortalecimento do agronegócio brasileiro" (FABRINI; ROOS, 2014, p. 22).

É nesse contexto - mesmo com a mobilização dos ruralistas - que os agricultores que cultivam o milho crioulo no "Território do Milho Crioulo de Ibarama” resistem à chamada modernização, na defesa da qualidade de vida, da produção de alimentos e da manutenção da autonomia do agricultor, produzindo suas sementes, com o direito de exercer o livre arbítrio sobre elas; porém, sem negar seu caráter universal de patrimônio da humanidade. É dessa forma que os agricultores pretendem continuar sustentando a sua prática agrícola, solidária e coletiva, com vistas a garantir a sustentabilidade.

\section{Considerações finais}

A intenção desse ensaio é demonstrar o quanto o milho crioulo possibilita a discussão acerca da sustentabilidade, bem como guarda relações com um modelo de desenvolvimento comprometido com as discussões que envolvem a qualidade de vida e a adequada preservação ambiental.

As duas experiências discutidas representam importantes espaços, que se constituem em territórios do milho crioulo, onde, além da utilização das sementes crioulas são utilizadas práticas e técnicas de cultivo que permitem a manutenção do equilíbrio ambiental e a preservação das relações sociais e culturais imbricadas no cultivo do milho crioulo.

No momento, no Brasil, está se construindo um modelo de agricultura tecnológico e capitalista, no qual o potencial é direcionado para a produção de commodities. Esse modelo de desenvolvimento no Brasil não contribui com a sustentabilidade, pois o aumento da produção é feito, também, com a expansão da fronteira agrícola, com o aumento na utilização de agroquímicos e a introdução crescente de sementes tecnológicas, como as híbridas e transgênicas.

Esse pacote tecnológico provoca problemas para a saúde das pessoas e o desequilíbrio ambiental, com reflexos sociais, pela exclusão de pequenos agricultores e, também, dos próprios trabalhadores rurais, que perdem a sua função de "produtor rural" para se tornarem consumidores do pacote tecnológico oferecido pelas empresas do setor.

Como a lógica desse modelo de agricultura é maximizar a produtividade, não há compromisso com a sustentabilidade e com a inclusão social, pois no centro dos interesses está o crescimento econômico. Para esse grupo, representado pelo agronegócio, é preciso produzir sempre mais e consumir também mais, sem dimensionar as consequências.

Genericamente é possível afirmar que o desenvolvimento sustentável tem como matriz a preservação ambiental e equilíbrio social. Portanto, para 
os que defendem esse modelo não é possível preocupar-se apenas com a produção, mas com o consumo e o destino dos resíduos, por exemplo.

Os agricultores que se identificam com o desenvolvimento sustentável praticam a agricultura em estilo camponês, com a prática da policultura, com a produção agroecológica e voltada prioritariamente para a produção de alimentos com qualidade, geralmente sem o uso de agrotóxicos. Esse modelo de agricultura sofre processo de invisibilidade, para que não "ameace" o modelo hegemônico da agricultura comercial e capitalista.

No entanto, para esses agricultores há uma importância fundamental que é o controle sobre as sementes, pois com elas é possível planejar o desenvolvimento e avaliar a melhor forma de se organizar, com autonomia e independência, evitando ficarem reféns do pacote tecnológico do agronegócio. Dessa forma, é possível garantir o desenvolvimento sustentável, a inclusão dos agricultores e promover melhorias nas condições do ambiente para a atual e as futuras gerações.

\section{Referências}

ALVES, Francelino Alves; CARRIJO, Beatriz Rodrigues; CANDIOTTO, Luciano Zanetti Pessôa (Org.). Desenvolvimento territorial e agroecologia. São Paulo: Expressão Popular, 2008.

ALTIERI, Miguel. Agroecologia: bases para uma agricultura sustentável. 3. ed. rev. ampl. São Paulo: Expressão Popular; Rio de Janeiro: AS-PTA, 2012.

AQUINO, Adriana Maria de; ASSIS, Renato Linhares de (Ed. Técnicos). Agroecologia: princípios e técnicas para uma agricultura sustentável. Brasília, DF: Embrapa, informação tecnológica, 2005.

BELIK, Walter. Perspectivas para segurança alimentar e nutricional no Brasil. [Revista] Saúde e Sociedade, v. 12, n. 1, p. 12-20, jan./jun. 2003. Disponível em: <http://www.scielo.br/pdf/sausoc/v12n1/04.pdf> Acesso em: 21 ago. 2014.

CANCI, Adriano. Sementes crioulas: construindo soberania. A semente na mão do agricultor. São Miguel do Oeste: Mclee, 2002.

CAMPOS, Antônio Valmor de. Milho Crioulo: sementes de Vida - pesquisa, melhoramento e propriedade intelectual. Frederico Westphalen/RS: Editora da URI, 2007.

CASSOL, Kelly Perlin. Construindo a autonomia: o caso da associação dos guardiões das sementes crioulas de Ibarama/RS.2013.130 p. Dissertação (Mestrado em Geografia) - Programa de Pós-graduação em Geografia, Universidade Federal de Santa Maria, Santa Maria, 2013.

CASTRO, Iná Elias de. Geografia e política: território, escalas de ação e instituições. Rio de Janeiro: Bertrand Brasil, 2005.

FABRINI, João Edmilson; ROOS, Djoni. Conflitos territoriais entre o campesinato e o agronegócio latifundiário. São Paulo: Outras Expressões, 2014. 
FERREIRA, Angela Duarte Damasco; BRANDENBURG, Alfio (Org.). Para pensar outra agricultura. Curitiba: Editora da UFPR, 1998.

GONÇALVES, Gabriel Moreno Bernardo. Caracterização e divergência genética de variedades crioulas de milho pipoca conservadas por agricultores do oeste de Santa Catarina. 2016. 139 p. Dissertação (Mestrado em Recursos Genéticos) - Programa de Pós-graduação em Recursos Genéticos. Universidade Federal de Santa Catarina, Florianópolis, 2016.

KHATOUNIAN, Carlos Américo. A reconstrução ecológica da agricultura. Botucatu: Agroecológica, 2001.

LOSEKANN, Marlise Beatriz. Saber e Identidade dos Agricultores Familiares Camponeses da "Costa do Bica" e "Paredão", Piratini/RS. 2011, 110 p. Dissertação (Mestrado em Geografia) - Programa de Pós-graduação em Geografia, Universidade Federal de Santa Maria. Santa Maria-RS, 2011.

MOREIRA, Antonio Carlos. Conquista na fronteira: desenvolvimento territorial com sustentabilidades. Frederico Westphalen/RS: Editora da URI - Frederico Westphalen, 2013.

OLIVEIRA, Iolanda Lopes et al. Agrobiodiversidade Crioula: os 13 anos dos Dias da Troca das Sementes Crioulas de Ibarama-RS. Cadernos de Agroecologia, v. 10, n. 3, 2015.

SANTA Catarina. Lei $\mathbf{n}^{\mathbf{0}} \mathbf{1 1 . 4 5 5}$, de 19 de junho de 2.000. Consolidada pela Lei no 16.722/2015. Concede o título de "capital estadual do milho crioulo", ao Município de Anchieta. Disponível em: <https://www.google.com.br/search?q=L ei $+n \% \mathrm{C} 2 \% \mathrm{BA}+11.455+\% 2 \mathrm{C}+\mathrm{de}+19+$ de + junho $+\mathrm{de}+2.000 \&$ oq $=\mathrm{Lei}+\mathrm{n} \% \mathrm{C} 2 \% \mathrm{BA}+$ $11.455+\% 2 \mathrm{C}+\mathrm{de}+19+$ de + junho + de $+2.000 \&$ aqs $=$ chrome..69i57.2441j0j8\&sourcei $\mathrm{d}=$ chrome\&ie $=U \mathrm{UTF}-8>$. Acesso em 19 de maio 2017.

SANTILLI, Juliana. Agrobiodiversidade e direitos dos agricultores. São Paulo: Petrópolis, 2009.

SANTOS, Milton; SOUZA, Adélia A. de; SILVEIRA, Maria Laura. Território, globalização e fragmentação. 4. ed. São Paulo: HUCITEC, 1998.

VIDAL, Rafael André. Diversidade das populações locais de milho de Anchieta e Guaraciaba, Oeste de Santa Catarina: múltiplas abordagens para sua compreensão. 2015. 190 p. Tese (Doutorado em Recursos Genéticos) Programa de Pós-Graduação em Recursos Genéticos, Universidade Federal de Santa Catarina, Florianópolis, 2015. Disponível em: <https://repositorio.ufsc.br/ bitstream/handle/123456789/172357/343401. pdf? sequence=1\&isAllowed=y>. Acesso em: 31 mar. 2017.

ZARTH, Paulo (Org.). História do campesinato na Fronteira Sul. Porto Alegre: Letra \& Vida: Chapecó: Universidade Federal da Fronteira Sul, 2012.

WACHOWICZ, Marcos. Direitos culturais e saberes: o reconhecimento de um direito de propriedade intelectual de natureza difusa. Políticas Culturaisem Revista, v. 1, n. 6, p. 220-234, 2013. Disponível em: <www.politicasculturaisemrevista.ufba. br>. Acesso em: 25 fev. 2017.

Submetido em: 26/10/2017

Aceito em: 27/07/2018 


\title{
SUSTAINABILITY INTHE TERRITORIES OF CRIOULO CORN: LOOKS AT ANCHIETA/SC AND IBARAMA/RS
}

\begin{abstract}
Sustainable development represents the expectation of better living conditions for the entire population. The expectation is to verify if in the territories of the Creole corn of Ibarama and Anchieta it is possible to identify aspects that contemplate this conception. Also, to check whether the farmers who grow maize are opting for a development model that has effective concerns with social and environmental balance. The results of the empirical research were analyzed from a perspective of sustainability that reconciles the economic growth with the cultural, associative organizations that prioritize the agricultural model of polyculture, agroecology and autonomy, using the creole seeds, mainly corn. This is visible in the "territories of the Creole corn", as in Ibarama/RS and Anchieta/SC. In these places, a group of farmers is organized to practice and defend sustainable development, which is achieved through the use of native seeds, especially corn. The researchers/authors carried out researches in these territories for the elaboration of their master's dissertations. In Anchieta the research carried out by author 1 occurred in the year of 2004. However, this brought him closer to that territory, keeping the visits in loco, until the completion of a doctorate in the same territory, completed this year. The second author concluded her master's degree in the territory of Ibarama in the year 2013. This allowed to know and analyze the activities developed by these farmers. The data were obtained from semi-structured interviews and from information gathered at meetings, meetings, visits and fairs on the Creole corn. It is also demonstrated the possibility that the cultivation of Creole maize is a catalyst for agricultural practices voted for sustainable development, with less environmental impact and better social justice.
\end{abstract}

Keywords: Sustainability. Creole corn. Territory of Crioulo Corn. Peasant farmers. 